\title{
Calculation of wooden beams on the stability of a flat bending shape enhancement
}

\author{
Anton Chepurnenko ${ }^{1,}$ Vera Ulianskaya ${ }^{1}$, Serdar Yazyev ${ }^{1}$, and Ivan Zotov ${ }^{1}$ \\ ${ }^{1}$ Don State Technical University, 192 Socialisticheskaya str., Rostov-on-Don, Russia
}

\begin{abstract}
Flat bending stability problem of constant rectangular cross section wooden beam, loaded by a distributed load is considered. Differential equation is provided for the cases when load is located not in the center of gravity. The solution of the equation is performed numerically by the method of finite differences. For the case of applying a load at the center of gravity, the problem reduces to a generalized secular equation. In other cases, the iterative algorithm developed by the authors is implemented, in the Matlab package. A relationship between the value of the critical force and the position of the load application point is obtained. A linear approximating function is selected for this dependence.
\end{abstract}

\section{Introduction}

For reasons of reducing wood consumption in rectangular section wooden beams design they try to increase the ratio of the cross section height to its width. The necessity of flat deformation shape stability test comes in this case $[1,2]$.

The problem of flat bending shape stability of constant rectangular section wooden beam is solved with following differential equation $[3,4]$ :

$$
G I_{t} \frac{d^{2} \theta}{d x^{2}}+\frac{M_{y}^{2}}{E I_{z}} \theta=0
$$

where $G$-shear modulus, $I_{t}$ - polar moment of inertia, $I_{z}$-axial moment of inertia, $M_{y}$ - bending moment, $\theta$ - angle of twist.

Equation (1) is written for the case when load is applied at cross section center of gravity. Current design standards of wooden structures [5] are based on the solutions of this equation for different options for securing the beam.

In A. Karamysheva dissertation [6] following differential equation was obtained, that considers variable beam stiffness, and loading not only in the center of gravity as well:

$$
G I_{t} \frac{d^{2} \theta}{d x^{2}}+\frac{d\left(G I_{t}\right)}{d x} \frac{d \theta}{d x}+\left(q a+\frac{M_{y}^{2}}{E I_{z}}\right) \theta=0,
$$

where $a$ - center of gravity to load location distance.

*Corresponding author: anton_chepurnenk@mail.ru 

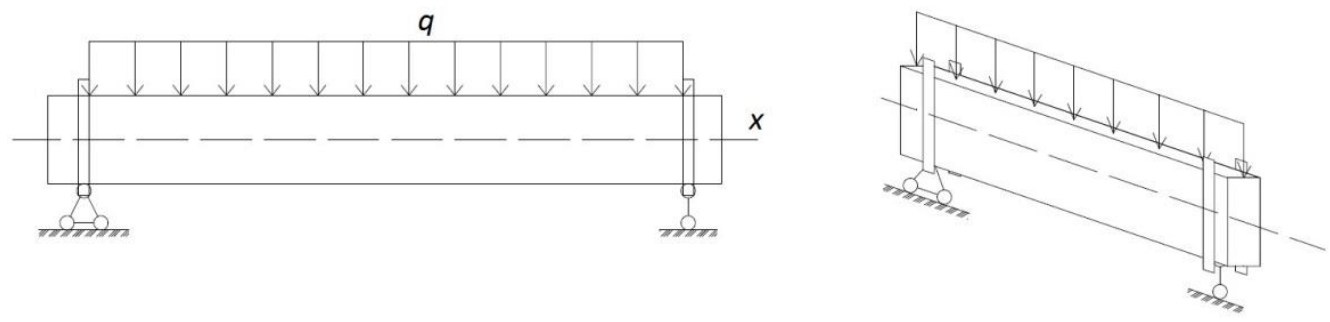

Fig. 1. A beam considered in the article

A. Karamysheva considered only two cases of a load applying not at the center of gravity: a cantilever beam with concentrated force at the end, and a hinged beam loaded with a concentrated force in the middle of the span. In the paper we consider a beam of constant cross-section loaded by a uniformly distributed load q (Figure 1). The second term of the equation (2) equals zero because the beam that we calculate has constant section.

\section{The derivation of the final equation}

Bending moment is determined by the following formula:

$$
M_{y}=\frac{q \cdot x}{2} \cdot(l-x)
$$

Inserting dimensionless coordinate $\xi=\frac{x}{l}$ and non-dimensional values

$$
\alpha=\frac{a}{l} \sqrt{\frac{E I_{z}}{G I_{k}}}, \lambda=\frac{q^{2} l^{6}}{G I_{k} E I_{z}},
$$

the equation can be represented in a form:

$$
\frac{d^{2} \theta}{d \xi^{2}}+(\sqrt{\lambda} \alpha+\lambda f(\xi)) \theta=0
$$

where $f(\xi)=\xi^{2}(1-\xi)^{2} / 4$.

Boundary conditions for the equation (4): $\theta(0)=0, \quad \theta(1)=0$.

The solution of equation (4) is performed numerically by the method of finite differences [7]. Uniform grid with $\Delta \xi$ - step is inserted. The finite differences approximation of equation (4) is written as [8]:

$$
\frac{\theta_{i+1}-2 \theta_{i}+\theta_{i-1}}{\Delta \xi^{2}}+\left(\sqrt{\lambda} \alpha+\lambda f\left(\xi_{i}\right)\right) \theta_{i}=0
$$

Constructing equation (5) for all internal nodes of the grid, we have a homogeneous system of linear algebraic equations:

$$
([A]+\sqrt{\lambda} \alpha[E]+\lambda[B])\{X\}=0,
$$

where $A=\frac{1}{\Delta \xi^{2}}\left[\begin{array}{lllll}-2 & 1 & 0 & \ldots & 0 \\ 1 & -2 & 1 & \ldots & 0 \\ 0 & 1 & -2 & \ldots & 0 \\ \ldots & \ldots & \ldots & \ldots & \ldots \\ 0 & 0 & 0 & 1 & -2\end{array}\right], B=\left[\begin{array}{llll}f\left(\xi_{2}\right) & 0 & \ldots & 0 \\ 0 & f\left(\xi_{3}\right) & \ldots & 0 \\ \ldots & \ldots & \ldots & \ldots \\ 0 & 0 & 0 & f\left(\xi_{n}\right)\end{array}\right], \quad X=\left\{\begin{array}{c}\theta_{2} \\ \theta_{3} \\ \ldots \\ \theta_{n}\end{array}\right\}$,

$[E]$ - unit matrix. 
The system (6) has a nonzero solution if its determinant is equal to zero:

$$
|[A]+\sqrt{\lambda} \alpha[E]+\lambda[B]|=0 .
$$

In the special case for $\alpha=0$, i.e. when the load is applied at the center of gravity, equation (7) represents a generalized secular equation. The first critical load corresponds to the minimum of the eigenvalues $\lambda$. The critical load can be determined by formula:

$$
q=\frac{\sqrt{\lambda} \sqrt{G I_{k} E I_{z}}}{l^{3}}=K \frac{\sqrt{G I_{k} E I_{z}}}{l^{3}} .
$$

\section{Method of calculation}

For $\alpha=0$ coefficient $K$ equals 28.3, and the eigenvalue $\lambda_{1}=800$. In the case when $\alpha \neq 0$ equation (7) is no longer a generalized secular equation. For its solution an iterative process was developed by authors, the essence of which is as follows.

In the first approximation, instead of equation (7), we solve the secular equation, which has the form:

$$
\left|\left[A_{1}\right]+\lambda[B]\right|=0,
$$

where $\left[A_{1}\right]=[A]+\sqrt{\lambda_{1}} \alpha[E]$.

As a result of the equation (9) solution we obtain the minimum eigenvalue $\lambda_{1}^{\prime}$. In second approximation we substitute $\lambda_{2}=\left(\lambda_{1}+\lambda_{1}^{\prime}\right) / 2$ instead of $\lambda_{1}$ in matrix $\left[A_{1}\right]$. The criterion for the iterative process termination is the condition:

$$
\frac{\left|\lambda_{i}-\lambda_{i}^{\prime}\right|}{\lambda_{i}} \cdot 100 \%<\varepsilon,
$$

where $\varepsilon$-predetermined error.

\section{Results and discussion}

The calculation was implemented in Matlab package. The resulting graph of the change in the coefficient $\mathrm{K}$, as a function of $\alpha$, is shown in Figure 2.

In the Microsoft Excel program, a linear approximating function was chosen for the dependency, which has the form:

$$
K=28,675-40,317 \alpha \text {. }
$$

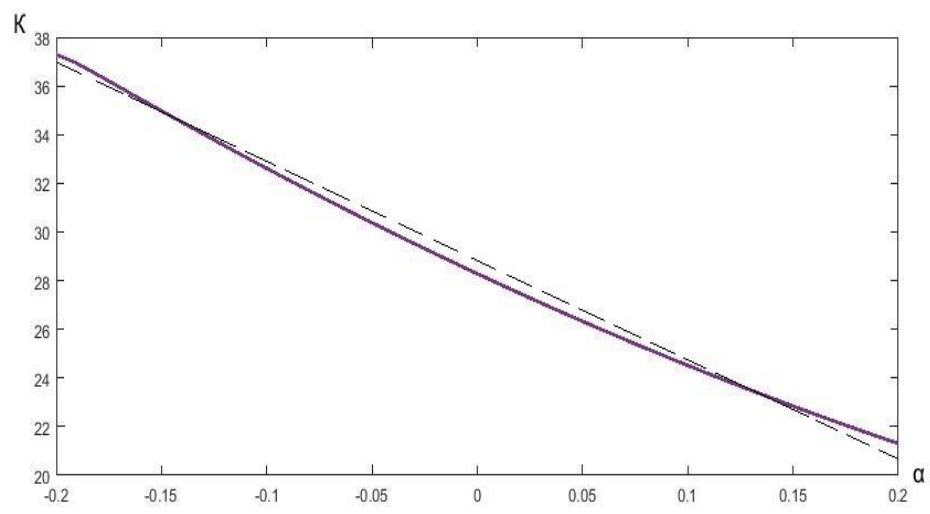

Fig. 2. Dependency graph of coefficient $K$ as a function of $\alpha$ 
As it is seen in the graph, when a load is applied above the center of gravity, its critical value decreases, and if the load is applied under the center of gravity, its critical value increases. The same dependency was observed in the calculation of wooden articulated beam, loaded with the concentrated force [9].

To verify the correctness of the results, a finite-element calculation of the wooden beam in the LIRA-SAPR 2013 program was performed. Initial data for the calculation: $b=1 \mathrm{~cm}$, $h=10 \mathrm{~cm}, l=2 \mathrm{~m}$. The orthotropy of the material was considered, the values of the elastic constants were assumed to be equal to: $E_{1}=10^{4} \mathrm{MPa}, E_{2}=400 \mathrm{MPa}, \mathrm{G}=500 \mathrm{MPa}, v_{12}=$ $0.018, v_{21}=0.45$. The beam was modeled by plane shell finite elements. For the case when load is applied at the center of gravity of the cross section, the value of critical load was found: $q_{\mathrm{cr}}=0.133 \mathrm{kN} / \mathrm{m}$ (Figure 3), and when the load is above the gravity center $q_{\mathrm{cr}}=0.123$ $\mathrm{kN} / \mathrm{m}$ (Figure 4). Theoretical values that were received using formula (9), equals 0.132 and $0.123 \mathrm{kN} / \mathrm{m}$. The coincidence of the results indicates their reliability.

\section{Load case 2}

Buckling mode in global system 1

Stab. factor 0.133428

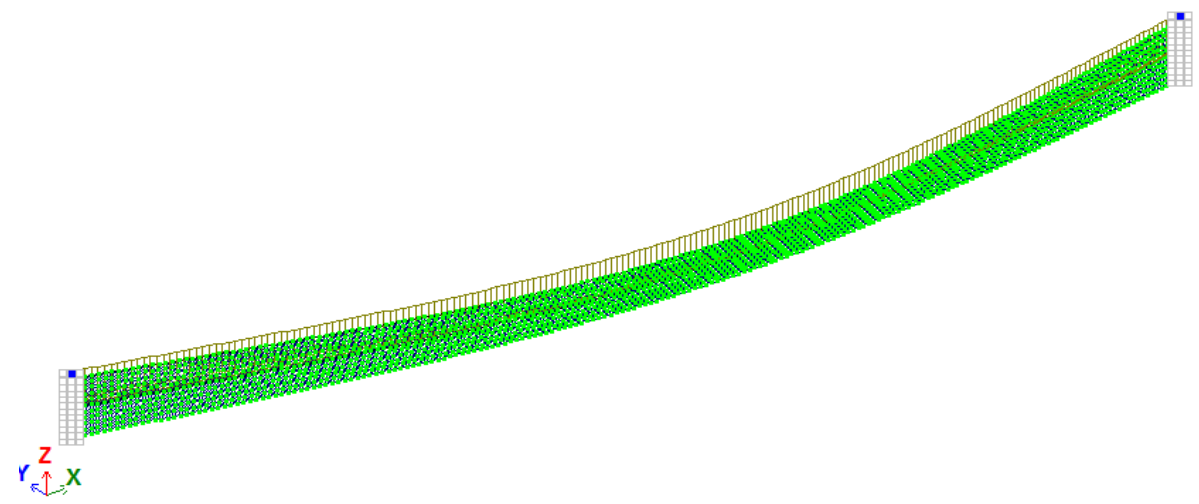

Fig. 3. Loss of stability for the case when a load is applied at the center of gravity of the cross section

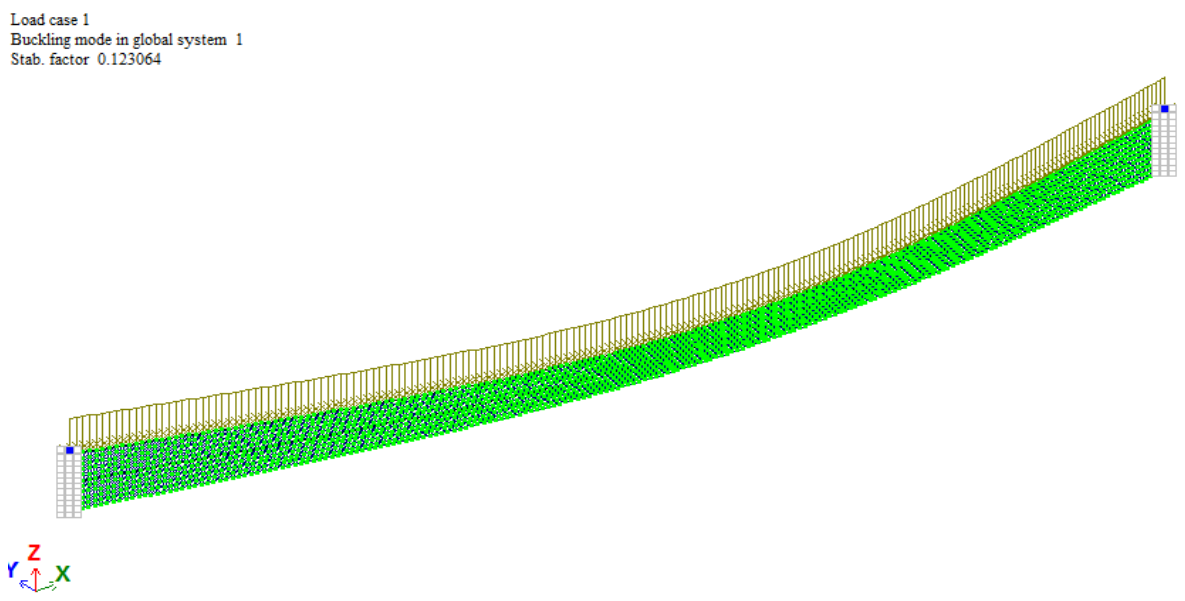

Fig. 4. Loss of stability for the case when a load is applied above the center of gravity of the cross section 


\section{References}

1. A. A. Karamysheva, B. M. Yazyev, A. S. Chepurnenko, S. B. Yazyeva, Inženernyj vestnik Dona, 3 (2015)

2. A. A. Karamysheva, S. B. Yazyev, A. A. Avakov, Procedia Engineering, 150, 18721877 (2016)

3. A. S. Volmir, Stability of deformable systems (Nauka, 1967)

4. S. P. Timoshenko, J. M. Gere, Theory of elastic stability (McGraw-Hill, 1961)

5. SP 64.13330.2017. Wooden structures. Updated version of SNiP II-25-80 (Moscow, 2017)

6. A. A. Karamysheva. Improvement of the calculation of the stability of the flat form of the bending of wooden beams of variable cross-section and their optimization: dissertation for the degree of candidate of technical sciences (Rostov-on-Don, 2016)

7. P.M. Varvak, L.P. Varvak. The method of grids in the problems of calculating building structures (Stroyizdat, 1977)

8. Quang A. Dang, Nguyen Thanh Huong, Advances in Numerical Analysis, 2013, 470258 (2013)

9. A.S. Chepurnenko, V.V. Ulianskaya, D.A. Vysokovsky, I.M. Zotov, Inženernyj vestnik Dona, 2 (2018) 